\title{
Prevention and control of micronutrient deficiencies in developing countries: current perspectives
}

This article was published in the following Dove Press journal:

Nutrition and Dietary Supplements

29 May 2014

Number of times this article has been viewed

\author{
Cristiana Berti' \\ Mieke Faber ${ }^{2}$ \\ Cornelius M Smuts' \\ 'Centre for Excellence in Nutrition, \\ North-West University, \\ Potchefstroom, South Africa; \\ ${ }^{2}$ Non-communicable Diseases \\ Research Unit, South African Medical \\ Research Council, Tygerberg, South \\ Africa
}

\begin{abstract}
Despite strategies employed to tackle micronutrient malnutrition, limited progress has been achieved in the developing countries. Of global concern are deficiencies in iron, vitamin A, zinc, folate, and iodine. This review aims to explore up-to-date scientific evidence on the effect of different micronutrient strategies on biomarkers and health outcomes, and for each strategy, to highlight strengths, limitations, and factors contributing to success or failure. PubMed/MEDLINE and EBSCO databases and Google-indexed scientific literature were searched for relevant articles and documents, limited to human studies reported since 2003. Evidence shows that the most cost-effective approaches to address symptoms of micronutrient malnutrition are targeted supplementation and/or fortification with iron, iodine, zinc, folic acid, vitamin A, and multimicronutrients, provided that households have access to primary health care and that there is consistent long-term coverage, monitoring, adequate marketing, and commercial commitment. Dietary diversification/modification interventions are probably the most sustainable strategies to address causes of deficiency, but permanent solutions are still required in controlling micronutrient malnutrition at both research and public health levels. Furthermore, many scientific gaps remain, hindering the development of robust public health guidance. These gaps are due to the paucity of well-designed community-based studies, lack of information on biological mechanisms behind relationships between micronutrients and outcomes, and inconsistent results. Further adequately powered long-term trials are needed to fill these gaps. Lessons learned from large-scale nutritional programs suggest that, for long-term improvements in nutrition and health, dietary strategies must integrate agricultural production with primary health care and female nutrition education and empowerment. They must also promote behaviors that support adequate intake, ensure availability of supply, and help to empower communities to become more self-reliant.
\end{abstract}

Keywords: fortification, supplementation, sustainability, integrated nutritional programs, resource-poor populations, dietary diversification

Micronutrient malnutrition, also known as hidden hunger, reduces learning and cognitive ability; impairs growth; reduces immunity; decreases working capacity; causes several pregnancy complications, blindness, and goiter; and raises the risk of mortality. ${ }^{1}$ The populations most at risk of such deficiencies are infants and children, women of reproductive age, pregnant women, and the elderly. ${ }^{2-5}$ Lack of dietary diversity (ie, monotonous diets), poor mineral bioavailability in plant foods, incidence of illness and disease, and increased physiological demands are the main contributors to micronutrient deficiencies. ${ }^{6,7}$ Of global concern are deficiencies in iron, vitamin A, zinc, folate, and iodine. The World Health Organization (WHO) reported that over two billion people are at risk of vitamin $\mathrm{A}$, iodine, and/or iron deficiency, with the most
Correspondence: Mieke Faber Non-communicable Diseases Research Unit, Medical Research Council, PO Box 19070, Tygerberg, 7505, South Africa

Tel +272l 9380404

Email mieke.faber@mrc.ac.za
Nutrition and Dietary Supplements 2014:6 4I-57 
severe problems found in developing countries. ${ }^{8}$ Black and coworkers $^{3}$ analyzed the global burden of disease attributable to nutritional factors for Africa, Asia, and Latin America in children under 5 years of age; they estimated that deficiencies of vitamin A and zinc accounted for the greatest burdens, responsible for 0.6 million and 0.4 million deaths, respectively, and a combined 9\% of global childhood disabilityadjusted life-years, whereas iron and iodine deficiencies resulted in relatively small death and disease burdens in children. Iron deficiency anemia is, however, an important risk factor for maternal mortality, and is estimated to cause annually 115,000 maternal deaths globally. ${ }^{9}$

Short-, intermediate-, and long-term sustainable solutions that are based on scientific evidence of both efficacy and effectiveness must be pursued to alleviate micronutrient malnutrition in developing countries. Although several approaches are practiced to address micronutrient malnutrition, micronutrient deficiencies remain a global challenge, which suggests that gaps remain to be filled at both research and public health levels.

This review aims to provide a critical and up-to-date overview of current information on existing interventions and strategies employed to improve the intake of micronutrients of global concern and tackle mineral and vitamin deficiencies in developing countries, and to highlight strengths, limitations, and factors contributing to success or failure of these strategies.

\section{Method}

This paper is a descriptive review. To obtain current information on the effect of micronutrient strategies on biomarkers and health outcomes, a search was conducted of PubMed/ MEDLINE and EBSCO databases, Google-indexed scientific literature, and WHO/Food and Agriculture Organization (FAO)/United Nations Children's Fund (UNICEF) documents. The search was limited to human studies published over the past 10 years (since 2003). Search terms were "micronutrient deficiency", "developing country", and "prevention OR control”. Randomized controlled trials (RCTs), observational studies, meta-analyses, and systematic reviews were included. Abstracts were critically evaluated to identify relevant articles focusing on efficacy and/or effectiveness of interventions, including experimental studies, national programs, and public health interventions with single or multiple micronutrients. Findings from original papers that were already discussed and analyzed in included systematic reviews and meta-analysis are not reported and discussed in this review. Despite some criticism, systematic reviews and meta-analyses are considered essential tools for summarizing evidence accurately and reliably. ${ }^{10}$ The reference lists of articles included in this review were examined for additional potential articles.

\section{Strategies addressing micronutrient malnutrition}

The most conventional and widely practiced strategies used to address micronutrient malnutrition are supplementation and food fortification. ${ }^{11}$ These strategies do not, however, address the primary cause of poor micronutrient status, inadequate dietary intake because of food insecurity, and may not be the most acceptable, accessible, or appropriate strategies for rural and/or ultra-poor households. Complementary strategies are needed in these contexts that support culturally appropriate dietary modification and community- and agriculture-based interventions, with simultaneous efforts to improve capacity and reach of supplementation and fortification. ${ }^{11,12}$

Tables 1 to 5 summarize available evidence on the effects of interventions using iron, ${ }^{13-25}$ folic acid, ${ }^{24,26}$ zinc, ${ }^{24,27-33}$ vitamin $A,,^{24,34-40}$ and multiple micronutrients ${ }^{24,41-50}$ on biomarkers and/or health outcomes. The majority of collected studies included pediatric populations and pregnant women. Most of these studies showed positive impacts on hematological indicators, while less clear effects were observed on health outcomes such as child development and growth or pregnancy outcomes. Although many studies focused on single nutrients, there are indications that multiple micronutrients may be more effective in improving micronutrient status and, for example, reducing anemia in school children (Table 5). Some limitations in the gathered findings (ie, for some micronutrients, the lack of strong scientific-based evidence of impact on health outcomes via a specific intervention) may exist, elicited by the combination of terms used to conduct the literature search.

\section{Supplementation}

Provision of large doses of micronutrients in highly absorbable form normally provides the fastest amelioration of the micronutrient status of individuals or targeted populations. Examples of such provisions include supplementation programs targeting anemia through iron supplementation (Table 1); folic acid supplementation in pregnant women (Table 2); and vitamin A supplementation in children younger than 5 years (Table 4 ).

\section{Pregnant women and lactating women}

Strong evidence exists that daily iron supplementation improves hemoglobin concentrations and iron stores, 


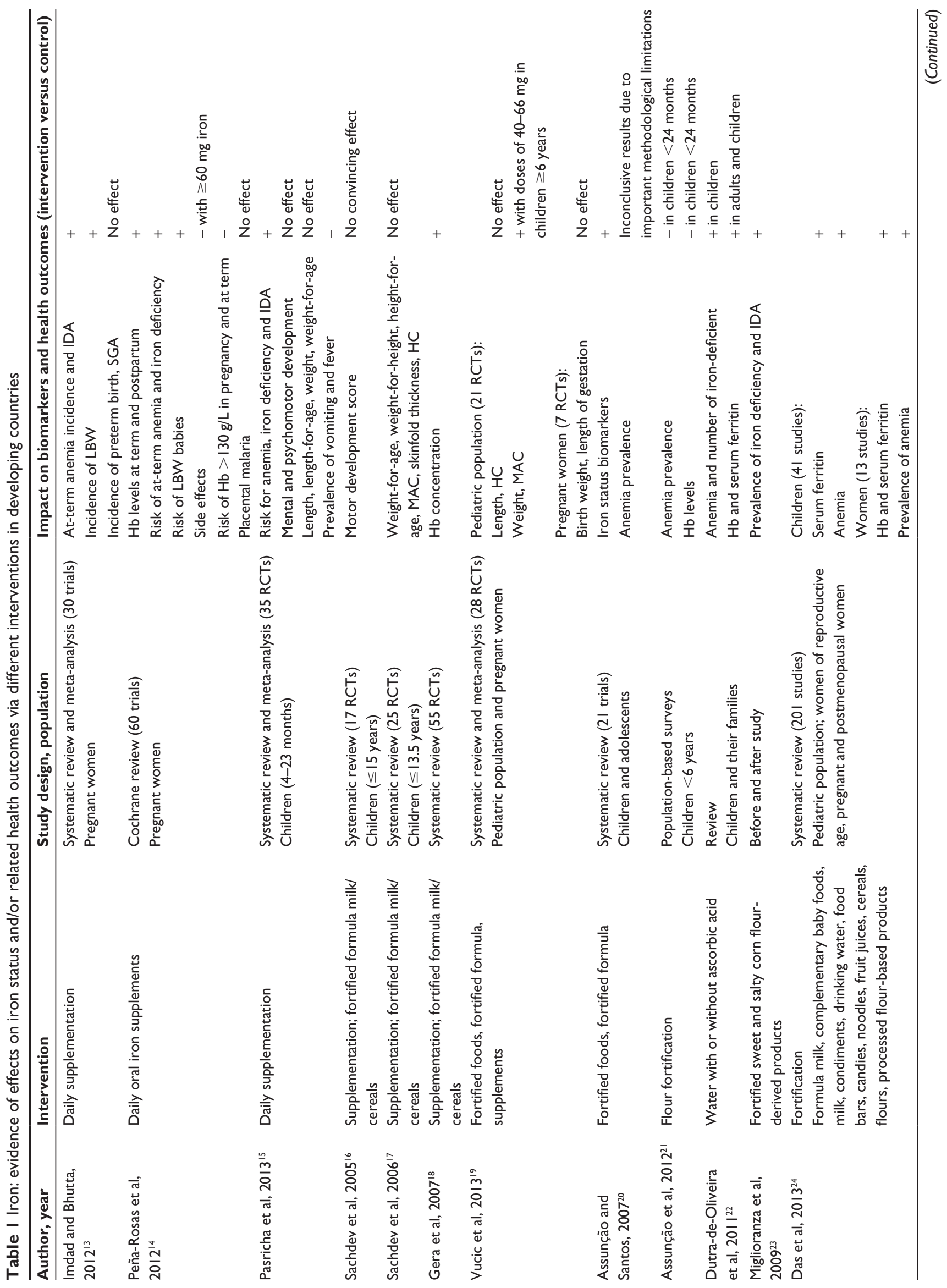


and reduces the risk of anemia, iron deficiency, and iron deficiency anemia during pregnancy. ${ }^{13,14}$ Routine iron supplementation is common during pregnancy, but potentially harmful effects (ie, increased small-for-gestational-age birth rate, hypertension disorders, gestational diabetes mellitus prevalence) in iron-sufficient women are debated because of conflicting results related to clinical end points, ${ }^{4,14}$ and side effects, particularly diarrhea, may occur at a daily dose $\geq 60 \mathrm{mg}$ elemental iron. ${ }^{14} \mathrm{~A}$ meta-analysis of 30 trials evidenced that preventive iron supplementation during pregnancy has significant benefit in reducing incidence of low birth weight (LBW), but not in reducing the incidence of preterm or small-for-gestational-age birth. ${ }^{13}$ No significant beneficial effect on birth weight and length of gestation is documented in the meta-analysis by Vucic and coworkers. ${ }^{19}$ Although the overall role of zinc on pregnancy outcomes is unclear, ${ }^{51}$ zinc supplementation significantly reduces the risk of preterm birth. ${ }^{29}$

Folic acid is of critical importance periconceptionally in protecting the fetus from neural tube and other congenital defects. ${ }^{4,24}$ Internationally, supplementation of $400 \mathrm{mg}$ /day of folic acid starting at least 4 weeks before conception and during the first trimester of pregnancy is recommended for preventing neural tube defects. Periconceptional supplementation of $800 \mathrm{mg} /$ day of folic acid combined with multivitamins has achieved a near $100 \%$ reduction of neural tube defects as well as marked reductions of congenital heart defects. ${ }^{52}$ By contrast, there is a paucity of well-conducted RCTs investigating the effect of folic acid supplementation on health outcomes in pregnancy. A meta-analysis of ten RCTs found a $2 \%$ increase in birth weight for every twofold increase in folate intake, but no beneficial effect of folate supplementation on placental weight or on length of gestation. ${ }^{26}$

During pregnancy, multimicronutrient (MMN) supplementation has similar beneficial effects to iron supplements, with or without folic acid, in terms of increased hemoglobin synthesis and reduced maternal anemia. ${ }^{41,53}$ Compared with iron/folic acid supplementation, maternal MMN supplementation in low-income countries resulted in a small rise in birth weight and reduction in the incidence of $\mathrm{LBW}^{42}$

The WHO does not recommend vitamin A supplementation during pregnancy as part of routine antenatal care for the prevention of maternal and infant morbidity and mortality, but in areas where vitamin A deficiency is a severe public health problem, vitamin A supplementation during pregnancy is recommended for the prevention of night blindness. ${ }^{54}$ Vitamin A supplementation in postpartum women for the 
Table 2 Folic acid and iodine: evidence of effects on biomarkers of status and/or related health outcomes via different interventions in developing countries

\begin{tabular}{|c|c|c|c|c|}
\hline \multirow{2}{*}{$\begin{array}{l}\text { Author, } \\
\text { year } \\
\text { Folic acid }\end{array}$} & \multirow[t]{2}{*}{ Intervention } & \multirow[t]{2}{*}{ Study design, population } & \multicolumn{2}{|c|}{$\begin{array}{l}\text { Impacts on biomarkers and health outcomes } \\
\text { (intervention versus control) }\end{array}$} \\
\hline & & & & \\
\hline $\begin{array}{l}\text { Fekete et al, } \\
2012^{26}\end{array}$ & Supplementation & $\begin{array}{l}\text { Systematic review and meta- } \\
\text { analysis ( } 10 \text { RCTs) } \\
\text { Pregnant women }\end{array}$ & $\begin{array}{l}\text { Birth weight } \\
\text { Placental weight, length of gestation }\end{array}$ & $\begin{array}{l}+ \\
\text { No effect }\end{array}$ \\
\hline \multirow{3}{*}{$\begin{array}{l}\text { Das et al, } \\
2013^{24}\end{array}$} & Fortification & Systematic review (20I studies) & Women (3I studies) & \\
\hline & $\begin{array}{l}\text { Mass fortification of } \\
\text { flour and processed }\end{array}$ & $\begin{array}{l}\text { Pediatric population; WRA, } \\
\text { pregnant and postmenopausal }\end{array}$ & $\begin{array}{l}\text { Neural-tube defects, spina bifida, } \\
\text { and anencephaly }\end{array}$ & + \\
\hline & flour-based products & women & $\mathrm{RBC}$ folate, serum folate & No effect \\
\hline \multicolumn{5}{|l|}{ lodine } \\
\hline \multirow{15}{*}{$\begin{array}{l}\text { Das et al, } \\
2013^{24}\end{array}$} & Mass salt fortification & Systematic review (20I studies) & Children (7 studies): & \\
\hline & programs & Pediatric population; WRA, & Urinary iodine & + \\
\hline & & pregnant and postmenopausal & Serum thyroxin levels & No effect \\
\hline & & women & Women (16 studies): & \\
\hline & & & Urinary iodine & + \\
\hline & & & Incidence of hypothyroidism & + \\
\hline & & & Serum thyroxin & No effect \\
\hline & & & Women (I 3 RCTs): & \\
\hline & & & Serum 25-hydroxy-D3 and & + in postmenopausal \\
\hline & & & parathyroid hormone & women \\
\hline & & & Serum levels of bone & + in WRA and \\
\hline & & & resorption markers & $\begin{array}{l}\text { postmenopausal } \\
\text { women }\end{array}$ \\
\hline & & & Maternal death or serious morbidity & + \\
\hline & & & Risk of preterm birth & + \\
\hline & & & $\begin{array}{l}\text { Risk of stillbirth or death before } \\
\text { discharge from hospital }\end{array}$ & No effect \\
\hline
\end{tabular}

Note: + beneficial effect.

Abbreviations: RBC, red blood cell; RCTs, randomized controlled trials; WRA, women of reproductive age.

prevention of maternal and infant morbidity and mortality is also no longer recommended. ${ }^{55}$

\section{Children}

The efficacy of iron in increasing hemoglobin concentrations has also been seen in children, with greater increases in children who are anemic at the start of the trial and lower increases in malarial hyperendemic areas. ${ }^{18}$ Iron supplementation seems to have no effects on the overall physical growth of infants or children. ${ }^{17,19}$ Although iron supplementation modestly improves mental development scores, particularly in children older than 7 years and those who were initially anemic or iron deficient, ${ }^{16}$ no convincing evidence has been found that iron supplementation has an effect on mental development in children younger than 27 months, or on motor development in children. ${ }^{15,16}$ Adverse events may occur during iron supplementation, such as fever and vomiting. ${ }^{15}$ Although there is some concern regarding the safety of population-based iron supplementation for children in malaria endemic areas, ${ }^{56}$ a systematic review of 71 trials concluded that there is no increased risk of clinical malaria or death when regular malaria surveillance and treatment services are provided. ${ }^{57}$ This is in line with the WHO recommendation that provision of iron to children in malaria-endemic areas be done in conjunction with measures to prevent, diagnose, and treat malaria. ${ }^{56}$

In line with other authors, ${ }^{58}$ findings collected in the present review clearly indicate that supplementation with zinc in young children can significantly reduce the rate, duration, and severity of diarrhea, as well as the rate of pneumonia (see Table 3).

The efficacy of vitamin A supplementation in preventing death and illness in children aged 6 months to 5 years is well established in developing countries. ${ }^{34,59}$ A positive association between receipt of a vitamin A supplement and undernutrition-related morbidity and/or mortality among children aged 12-59 months was recorded in national vitamin A supplement programs in Nepal, India, and Bangladesh. ${ }^{36,37,60}$ Some evidence indicates a potential beneficial effect of supplementing neonates at birth for reducing mortality in the first 6 months, ${ }^{35}$ but caution is suggested 
Table 3 Zinc: evidence of effects on biomarkers of status and/or related health outcomes via different interventions in developing countries

\begin{tabular}{|c|c|c|c|c|}
\hline $\begin{array}{l}\text { Author, } \\
\text { year }\end{array}$ & Intervention & Study design, population & $\begin{array}{l}\text { Impacts on biomarkers and health outc } \\
\text { (intervention vs control) }\end{array}$ & comes \\
\hline $\begin{array}{l}\text { Luabeya } \\
\text { et al, } 2007^{27}\end{array}$ & $\begin{array}{l}\text { Daily supplementation of vitamin A } \\
\text { alone vs (vitamin A plus zinc) vs } \\
\text { (vitamin A plus zinc plus MMN) }\end{array}$ & $\begin{array}{l}\text { RCT } \\
\text { Children (6-24 months) }\end{array}$ & Diarrhea and respiratory disease morbidity & No effect \\
\hline $\begin{array}{l}\text { Walker and } \\
\text { Black, } 2010^{28}\end{array}$ & $\begin{array}{l}\text { Supplementation (alone or in } \\
\text { combination) }\end{array}$ & $\begin{array}{l}\text { Systematic review } \\
\text { Infants and children } \\
\text { (I-59 months) }\end{array}$ & $\begin{array}{l}\text { Proportion of diarrheal episodes beyond } \\
7 \text { days; risk of hospitalization; all-cause } \\
\text { mortality; diarrhea mortality }\end{array}$ & + \\
\hline $\begin{array}{l}\text { Chaffee and } \\
\text { King, } 2012^{29}\end{array}$ & Daily supplementation & $\begin{array}{l}\text { Meta-analysis } \\
\text { Pregnant women }\end{array}$ & $\begin{array}{l}\text { Risk of preterm birth } \\
\text { Parameter of fetal growth (risk of LBW, } \\
\text { birth weight, length at birth, or HC at birth) }\end{array}$ & $\begin{array}{l}+ \\
\text { No effect }\end{array}$ \\
\hline $\begin{array}{l}\text { Aggarwal } \\
\text { et al, } 2007^{30}\end{array}$ & Supplementation & $\begin{array}{l}\text { Meta-analysis } \\
\text { Infants and children } \\
\text { ( } \leq 41 \text { months })\end{array}$ & $\begin{array}{l}\text { Episodes of diarrhea, severe diarrhea or } \\
\text { dysentery, persistent diarrhea } \\
\text { Episodes of respiratory tract infection or } \\
\text { pneumonia }\end{array}$ & $\begin{array}{l}+ \\
+\end{array}$ \\
\hline $\begin{array}{l}\text { Roth et al, } \\
2010^{31}\end{array}$ & $\begin{array}{l}\text { Routine (ie, daily or weekly) } \\
\text { supplementation }\end{array}$ & $\begin{array}{l}\text { Meta-analysis } \\
\text { Children }(<5 \text { years })\end{array}$ & $\begin{array}{l}\text { Incidence of ALRI defined by specific } \\
\text { clinical criteria }\end{array}$ & + \\
\hline $\begin{array}{l}\text { Soofi et al, } \\
2013^{32}\end{array}$ & $\begin{array}{l}\text { Provision of two micronutrient } \\
\text { powder formulations, with or } \\
\text { without zinc }\end{array}$ & $\begin{array}{l}\text { Cluster randomized trial } \\
\text { Children (6-18 months) }\end{array}$ & $\begin{array}{l}\text { Risk of iron deficiency anemia at } 18 \text { months } \\
\text { Height } \\
\text { Proportion of days with diarrhea, incidence } \\
\text { of bloody diarrhea, reported chest indrawing } \\
\text { Incidence of febrile episodes or admission } \\
\text { to hospital for diarrhea, respiratory } \\
\text { problems, or febrile episodes }\end{array}$ & $\begin{array}{l}\text { + for both MNP } \\
\text { groups } \\
\text { + mainly in } \\
\text { MNP-zinc group } \\
\text { - in both MNP } \\
\text { groups } \\
\text { No effect }\end{array}$ \\
\hline Das et al, & Fortification & Systematic review (20I studies) & Children (10 studies): & \\
\hline $2013^{24}$ & $\begin{array}{l}\text { Infant formula feeds or milk; } \\
\text { porridge, bread }\end{array}$ & $\begin{array}{l}\text { Pediatric population; women of } \\
\text { reproductive age, pregnant and } \\
\text { postmenopausal women }\end{array}$ & $\begin{array}{l}\text { Serum zinc } \\
\text { Height velocity, weight, Hb levels, } \\
\text { serum copper levels }\end{array}$ & + \\
\hline $\begin{array}{l}\text { Rosado et al, } \\
2009^{33}\end{array}$ & Biofortification of wheat & $\begin{array}{l}\text { Short-term, cross-sectional study } \\
\text { Women }\end{array}$ & Zinc absorption & + \\
\hline
\end{tabular}

Notes: + beneficial effect; - adverse effect.

Abbreviations: ALRI, acute lower respiratory infection; Hb, hemoglobin; HC, head circumference; LBW, low birth weight; MMN, multiple micronutrient; MNP, micronutrient powders (sprinkles); RCTs, randomized controlled trials; vs, versus.

because of the small number of studies; further trials are needed to determine the most effective dose and frequency of supplementation.

The prevalence of clinical vitamin A deficiency has decreased dramatically in countries such as Bangladesh. ${ }^{60}$ There is some concern that massive-dose vitamin A supplementation in children who are not vitamin A deficient may increase the prevalence of lower respiratory tract infections. ${ }^{61}$ Consequently, some authors recently challenged the wisdom of regularly providing massive doses of vitamin A to children, especially those who are not vitamin A deficient, and suggested targeted rather than universal prophylactic mega dose vitamin A supplementation in preschool children. ${ }^{22,63}$ Data from India showed that the cost-effectiveness of semiannual megadose vitamin A supplementation as a remedy for xerophthalmia and vitamin A deficiency-related mortality in children was lower for states where prevalence of vitamin A deficiency was lower and where mortality due to vitamin A deficiency was lower. ${ }^{64}$

\section{Enabling factors and barriers of effectiveness}

Analysis of available supplementation programs show that provision of micronutrient supplementation is most effective when combined with other maternal and child health interventions through primary health care systems or health care delivery systems. ${ }^{60,65,66}$

\section{Vitamin A supplementation in children}

Integrated approaches are not only more effective, but also cheaper than stand-alone supplementation programs. ${ }^{67}$ Vitamin A supplements can be distributed to children aged 6-59 months through efforts such as the Expanded Program on Immunization, national health days, and special 







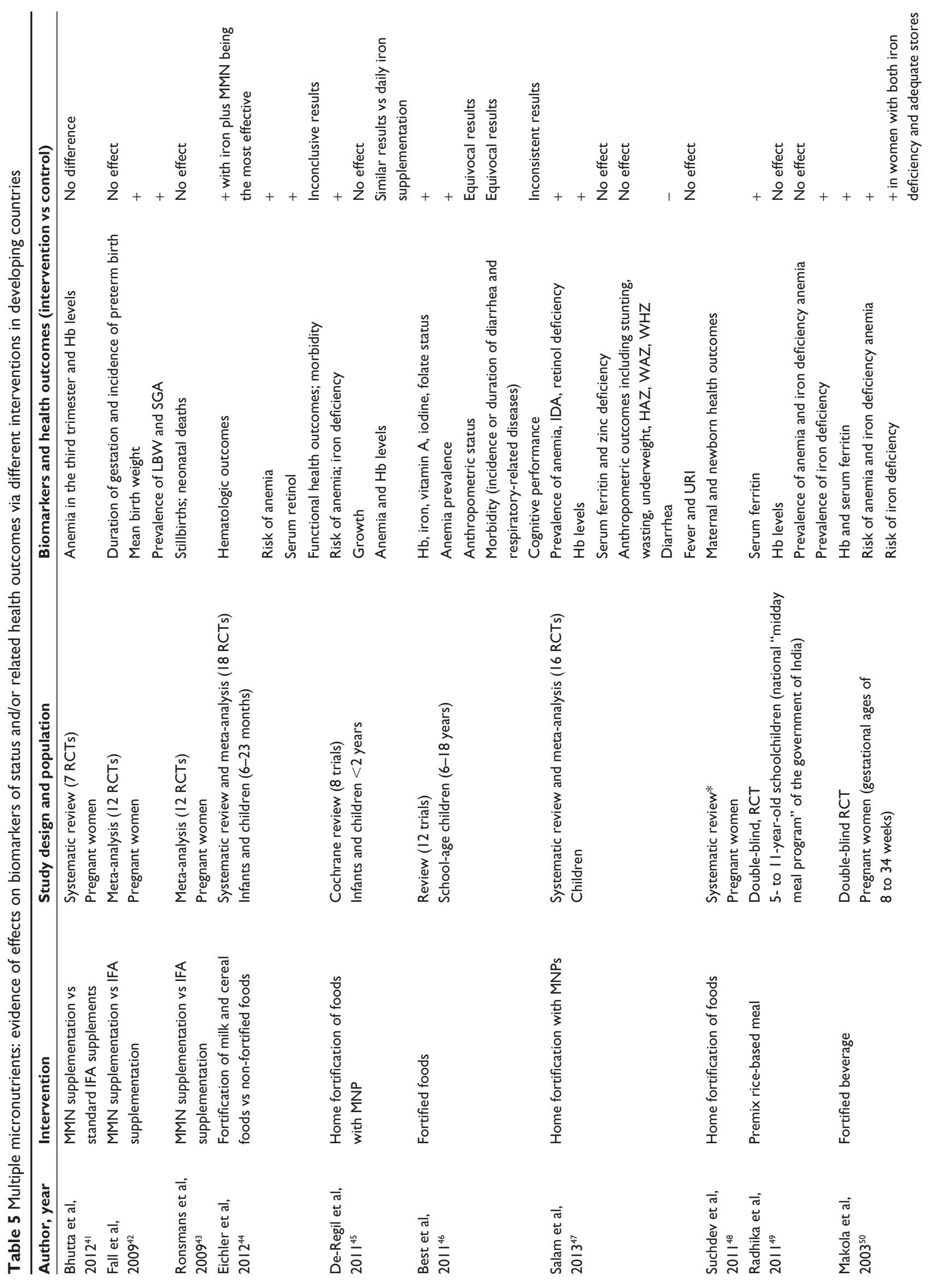




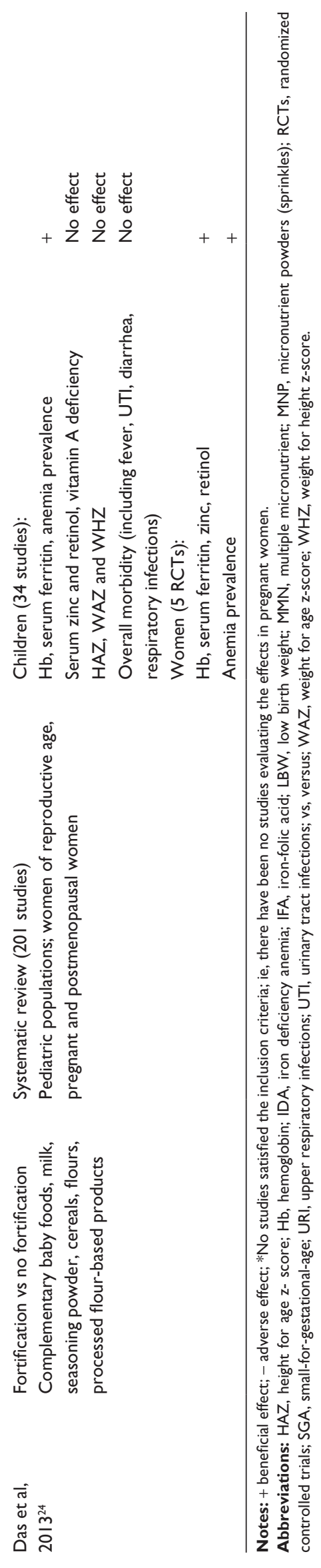

supplemental campaigns. ${ }^{38}$ In Bangladesh, children aged 9-11 months receive vitamin A capsules at the time of measles vaccination, and children aged $12-59$ months receive a massive-dose capsule every 6 months. In 2007, 88\% of children had received a vitamin A capsule during the last 6 months, but the coverage of postpartum vitamin A supplementation to mothers was only $20 \% .{ }^{60}$ In Nepal, vitamin A supplements are provided through community health workers, who also provide nutrition education, contraceptives, oral rehydration solution, and information on health and family planning $(80 \%-90 \%$ coverage is achieved in areas where the community health worker program is running). ${ }^{36}$ According to the 2005-2006 National Family Health Survey in India, only $20.2 \%$ of children had received a vitamin A capsule in the previous 6 months. ${ }^{37}$ In an attempt to improve coverage, the Bihar State in India successfully introduced community health workers to increase the coverage of vitamin A supplementation beyond the levels achieved through routine contact with the health system; this was made possible through the political decisions to assign human and program resources. ${ }^{68}$ According to $\mathrm{UNICEF}^{68}{ }^{6}$ itamin A supplementation coverage rates have shown dramatic increases over the past few years, and in $2008,71 \%$ of 6 - to 59 -month-old children in developing countries had received two doses of vitamin A.

Key elements for vitamin A supplementation coverage in both Nepal and India include maternal education and involvement of female community health workers. ${ }^{36-38}$ In Niger, key factors to the high coverage $(>80 \%)$ of the national vitamin A supplementation program are 1) leadership and ownership by the Ministry of Health; 2) district-level planning and implementation; 3) effective training and flexible delivery mechanisms; 4) effective social information, communication, and mobilization; and 5) responsiveness and flexibility of the Ministry of Health and development partners. ${ }^{69}$ The cost of the delivery system is the major costs of vitamin A supplementation programs, not the supplement itself. ${ }^{67}$

\section{Iron and folic acid supplementation during pregnancy}

Iron supplementation during pregnancy is usually delivered through antenatal care ${ }^{66}$ In Nicaragua, for example, iron-folic acid supplementation through antenatal care clinics resulted in a decline in the prevalence of anemia among reproductiveaged women from $33.6 \%$ in 1993 to $16.1 \%$ in 2003; over time, a coverage of iron and folic acid supplementation of $80 \%$ was reached and sustained. ${ }^{66}$ By contrast, in most countries the coverage of iron or iron-folic acid supplementation through antenatal care is inadequate, as overall iron supplementation programs tend to be less well developed 
to such an extent that limited recent global data exist on how many countries have such programs. ${ }^{70,71}$ An inadequate supply of iron tablets is often a major barrier. ${ }^{66}$ Coverage of antenatal care is often inequitable and missed opportunities for iron supplementation are much more common among the poor, as is reflected in data from Nepal, where in 2006 iron supplementation coverage was $34 \%$ in the poorest quintile and $80 \%$ in the wealthiest quintile. ${ }^{66}$ Moreover, there is a general lack of recognition of the importance of anemia in pregnancy, as well as inadequate counseling and distribution of iron tablets, and beliefs that oppose the consumption of medication during pregnancy. ${ }^{71}$

The analysis of the successful supplementation programs for pregnant women in Nicaragua and Nepal shows that key elements were antenatal care coverage, ensuring the distribution of tablets, improving compliance, providing extensive health worker training, ensuring counseling, involving community-based workers/volunteers, and using targeted communication programs to promote behavioral changes. ${ }^{66,71}$ Increased awareness about the role of micronutrients on health through training and education and the involvement of community health workers are also key elements of success. ${ }^{71}$

In summary, supplementation is the fastest way to control micronutrient deficiencies in individuals or population groups. Supplementation is, however, a temporary solution and does not address the underlying cause of nutrient deficiency. To achieve population impact and be most cost effective, micronutrient supplements should be distributed through the primary health care system. Major barriers to effective iron supplementation programs are inadequate counseling and distribution, difficulty of access, and poor utilization of health care services.

\section{Fortification}

A systematic review including 201 studies that assessed the effect of food fortification with single, dual, or multiple micronutrients in women and children concluded that food fortification is potentially an effective strategy to address micronutrient malnutrition. ${ }^{24}$ In some cases fortification is targeted toward foods that are eaten by specific population groups. In school children, for example, a systematic review of 12 studies showed beneficial effects of MMN-fortified foods (beverages, milk products, biscuits, seasoning powder) on child growth and cognitive domains related to memory and reduced morbidity from diarrhea and respiratory infections. ${ }^{46}$ Confirming data by Das and coworkers, ${ }^{24}$ a systematic review of 60 studies showed that iron-fortified foods such as milk, wheat/rice/corn flour and processed derivatives, sugar, and water exerted beneficial effects on iron status of children, depending on the choice of fortification vehicle and the iron compound used; ${ }^{25}$ no effects were found on physical growth or mental-motor development in pediatric populations. The evidence regarding beneficial effects on anemia in children is conflicting, apparently because of methodological limitations, ${ }^{20}$ with few studies indicating decreased prevalence. ${ }^{22,23}$ While improvements in short-term nutritional outcomes are consistent, evidence seems inconclusive regarding measurable impacts on functional health outcomes of growth, morbidity, and cognitive development. ${ }^{44}$

\section{Mass fortification}

With mass fortification at a national level, the focus is on foods that are widely consumed in constant and sufficient amounts by the majority of the target population. ${ }^{72}$ Examples of fortified foods in developing countries are salt (with iodine) and wheat or maize flour (with several micronutrients). Iodization of salt has been shown to significantly decrease the incidence of hypothyroidism, while folic acid-fortified flour has been shown to significantly reduce neural-tube defects and other congenital abnormalities. ${ }^{24}$ Traditional condiments and seasonings (eg, soy and fish sauces or curry powder) have been proposed as fortification vehicles, mainly in countries where they are widely consumed. ${ }^{73}$ In Vietnamese women, for example, consumption of fortified fish oil was shown to improve iron status and reduce the prevalence of anemia. $^{74,75}$

In Guatemala, fortification of sugar with vitamin A has led to a dramatic reduction in the prevalence rates of vitamin A deficiency. ${ }^{72}$ In Uganda, vegetable oil is fortified with vitamin A. ${ }^{76}$ In Brazil, fortifying potable water with iron has been shown to be efficient in reducing iron deficiency and anemia in infants and small children, and was also shown to be feasible and easily implemented at the community level. ${ }^{22}$

\section{Enabling factors and barriers of effectiveness}

Programs using iodized salt to prevent iodine deficiency are recognized as a major global public-health success. ${ }^{24}$ Andersson and coworkers ${ }^{77}$ reported that globally, iodine nutrition has been improving at national levels from 2003 to 2011, yet negligible progress was observed in Africa. An exception is the salt iodization program in Nigeria, where $98 \%$ of households were consuming iodized salt in 2008 , compared to $40 \%$ in 1993 when the program was launched; goiter prevalence declined from $67 \%$ in 1988 to $7.7 \%$ 
in $2005 .{ }^{66}$ Several factors contributed toward the success of this program: salt was universally consumed; there were few industries and ports of entry, which facilitates enforcement; private sector awareness, partnerships, coordination, and technical capacity were strong; and monitoring was conducted at all levels, from producers and importers to population surveys. ${ }^{66}$ In 2011, an excessive intake of iodine was observed in eleven countries, highlighting the importance of regular monitoring of iodine status to detect both low and excessive intake of iodine. ${ }^{77}$ Challenges in salt iodization programs are, reaching economically disadvantaged groups living in remote areas, and convincing the food industry and small-scale producers to iodize their salt. ${ }^{77}$

\section{Fortification vehicle}

The choice of fortification vehicle affects the impact of food fortification on iron outcome indicators. ${ }^{25}$ The selection of a vehicle food for a fortification program requires consideration of the matrix of the food, as this could affect the fortificant bioavailability; the dietary habits of the target population; and the cost of the intervention. The vehicle food must be commonly consumed in constant but sufficient amounts by a large proportion of the target population; accessible and available; considered feasible for the addition of bioavailable fortificants; and be produced in a few centralized sites. ${ }^{72,78}$ Mass fortification of staple foods is generally designed for the adult population, which is expected to consume a larger amount of flour-processed products than children. Because infants and small children consume relatively small amounts of food, mass flour fortification has little impact in this age group..$^{21,66}$ The importance of the vehicle food is further illustrated in data from Guatemala, which showed that the consumption of fortified wheat flour was about 15 times higher among nonpoor than among extremely poor families because rural indigenous populations in the highlands tend to consume corn rather than wheat. ${ }^{66}$ The vehicle food may also affect the cost of the fortification; for example, a vitamin A compound needed for fortification of dry matrixes (eg, flour) is at least four times more expensive than the oily forms. ${ }^{72}$ Data from Uganda suggest that fortifying vegetable oil with vitamin $\mathrm{A}$ is 4.6 times more cost effective than fortifying sugar with vitamin $\mathrm{A} .^{76}$

\section{Fortificant}

Fortification costs constitute approximately $80 \%$ of total fortification program cost. ${ }^{67}$ Successful food fortification programs require high bioavailability of micronutrient compounds to be used in fortified products; furthermore, the fortificant must be stable, have a long shelf life, and should not alter the color, taste, or appearance of the food..$^{79}$ For nutrients such as iron, bioavailability in fortified foods is of critical importance. The iron compound used for fortification may, in fact, affect the iron outcome indicators. ${ }^{25}$ In Brazil, for example, mandatory flour fortification was shown to be ineffective in reducing the prevalence of anemia in children, probably because of the low bioavailability of the fortificant used..$^{21}$ Hurrell and coworkers ${ }^{80}$ evaluated 78 national wheat flour programs for their potential impact on the iron status of the population, and concluded that only nine of these programs were likely to have a significant positive impact if coverage were optimized. Barriers for a positive impact of fortification programs were the use of nonrecommended, low-cost, low-bioavailability fortificants; low fortification levels; and low coverage. ${ }^{80}$ Effective fortification programs usually require legislation that mandates the private sector to comply with the fortification guidelines; governments play a critical role in quality assurance, monitoring, and enforcement of fortification regulations. ${ }^{67}$

\section{Home fortification}

Home (point of use) fortification represents a novel and innovative approach for fortifying foods at the household level using three types of food supplements: ${ }^{11,81} 1$ ) foodlets, which are crushable or water-soluble micronutrient tablets; 2) sprinkles, which are single-dose packets containing multiple vitamins and minerals in powder form (MNP) that can be sprinkled onto any semisolid food; and 3) lipid-based nutrient supplements, which are micronutrient-fortified lipidbased spreads/pastes providing energy, protein, and essential fatty acids in addition to vitamins and minerals. A foodlet providing daily multiple micronutrients was shown to be efficacious for controlling anemia and iron deficiency in a four-country multicenter study. ${ }^{82}$ Micronutrient powders/ sprinkles were also shown to be efficacious in reducing anemia and iron deficiency in infants and children under two, and seem to be as efficacious as the commonly used daily iron supplementation. ${ }^{45,47}$ Home-fortified complementary foods did not, however, exert any benefit on child growth ${ }^{45,47}$ and were associated with increased incidence of diarrhea. ${ }^{32,47}$ Further research is needed on proper use (daily or intermittent), the optimal vitamin and mineral composition of the powder, and the way to deliver this intervention effectively in public health programs.

Products used for home fortification are usually unfamiliar to the target population. Before large-scale implementation, assessing acceptance of these products within a given 
sociocultural context and gathering of information on the type of information that needs to be provided to improve adherence is important, as this may improve compliance. ${ }^{83}$ Thorough training of staff, social marketing, community mobilization, continued monitoring, and prompt management of adverse events are important. ${ }^{84,85}$ Although the risk of toxicity because of excessive intake is low, packing the product in single-dose sachets, rather than larger containers, could be beneficial; labeling is important to ensure correct use by the target population. ${ }^{84}$ Scaling up requires a reliable high-quality supply of the product and sustainable distribution systems that are able to reach the most vulnerable populations. ${ }^{86}$ Data from a pilot study in India showed that it is feasible to distribute sprinkles through an existing program (the Integrated Child Development Services, which is the largest child nutrition program in the world). ${ }^{85}$ For market-based community distribution, continued promotion and monitoring are essential. ${ }^{87}$ Home fortification strategies use home-prepared food as a vehicle; it is therefore important to cover topics on hygienic preparation of complementary foods and hand washing in the behavioral and communication campaigns that promote appropriate use of MNP. ${ }^{45}$ In general, it is strongly recommended to use food-based approaches in conjunction with public health interventions such as promotion and support of breastfeeding, control of infectious and parasitic diseases, education, and sanitation. ${ }^{88}$ Products used for home fortification of complementary foods in children younger than 2 years of age should not be seen as a replacement for breast milk and/or a varied diet, and should not be used as a breast milk substitute.

In summary, food fortification can reach a large sector of the population through existing food delivery systems, but the impact will depend on the fortification vehicle and the fortificant used. Home fortification is an innovative approach, but further investigation is required to evaluate its impact on health outcomes, as well as the way to deliver this intervention effectively in public health programs. Food fortification programs continue to face structural hurdles, as they require political support and long-term commercial commitment. Fortification strategies further require appropriate technical capacity, social marketing, community mobilization, private-sector awareness, partnerships, coordination, and continued monitoring.

\section{Nutrition-sensitive agricultural interventions}

Resource-poor populations generally consume monotonous diets that are predominantly cereal-based (thus high in phytate and phenolic compounds that inhibit iron and zinc absorption) and include few or no animal products, vegetables, or fruits. Moreover, in resource-poor households, micronutrient supplements and/or fortified foods may often be insufficiently accessible. The ultimate aim is therefore to improve dietary intake and monitor dietary quality. Strategies aimed at improving the availability, access to, production, and utilization of locally available foods with high micronutrient content and bioavailability that achieve desired micronutrient intakes and health outcomes need to be an integral part of any sustainable strategy to control micronutrient deficiencies. ${ }^{5}$ Improving dietary quality is considered the most desirable and sustainable option, but it takes the longest time to implement. ${ }^{78} \mathrm{~A}$ variety of approaches are included in these types of strategy, ranging from changes in eating behavior through communications, social marketing, or nutrition education ${ }^{89,90}$ and changes in traditional domestic methods for preparing and processing indigenous foods ${ }^{11}$ to the development of gardening, small animal husbandry, and aquaculture (fish ponds) in the homestead. ${ }^{5,11}$ Strategies discussed below are biofortification of staple foods and local production of micronutrient-rich foods. It should be noted that there is a strong linkage between these two strategies.

\section{Biofortification}

Biofortification (the process of enhancing the nutrient content of staple crops through traditional breeding and modern technology) is a novel agricultural approach to reduce micronutrient malnutrition. ${ }^{91}$ Biofortified varieties of rice, wheat, maize, cassava, pearl millet, beans, and sweet potato are currently being developed under the HarvestPlus Challenge Program, ${ }^{92}$ with conventional breeding being the primary focus to increase the content of iron, zinc, and provitamin A carotenoids. ${ }^{93}$ The amount of micronutrients that can be provided by biofortified staple foods is much lower than the amount that can be achieved by supplementation or food fortification. The potential benefit of biofortification depends on the amount of the staple food consumed per day. ${ }^{92}$ To be successful in reducing micronutrient malnutrition in developing countries, a biofortified crop must be high yielding and profitable to the farmer, be shown to be efficacious and effective at reducing micronutrient malnutrition, and be acceptable to both farmers and consumers in target regions. ${ }^{94}$ Successful introduction of biofortified foods requires knowledge of food production, seed and rural extension systems, and consumer preferences, ${ }^{93}$ combined with demand creation/behavior change and marketing through training of household members. ${ }^{39,40}$ Biofortification particularly targets local production in rural areas and 
may be a sustainable and feasible means of reaching poor rural families with limited access to markets and health care facilities (ie, to fortified foods and nutritional supplements) ${ }^{94}$ Interventions promoting biofortified crops are rural-based and, by design, initially reach more remote populations, but as production surpluses are marketed, the biofortified crops penetrate to urban populations. ${ }^{92}$

To date, dissemination of biofortified crops is limited to orange sweet potato, which is high in provitamin A. ${ }^{94}$ Some large-scale community-level programs introducing orangefleshed sweet potato in rural African farming households increased the vitamin A intake in children effectively. ${ }^{39,40}$ Evidence about the effects of the other biofortified crops on biological and/or functional indicators of micronutrient status is not yet fully established, as few efficacy studies with biofortified staple foods have been conducted. However, initial bioavailability and efficacy results are promising. ${ }^{33,92}$ Most of the existing trials are absorption studies aiming to evaluate the bioavailability of the nutrients involved, particularly iron and zinc. For example, iron bioavailability in Common bean (an important staple crop consumed in Africa and Latin America) represents a challenge for biofortification because of the high content of iron absorption inhibitors. ${ }^{95}$ Three studies compared iron absorption from either, high and normal iron beans, or high and low polyphenols beans, in women with low iron status and showed that there was no difference in the amount of iron absorbed from composite meals containing either high iron beans or normal iron beans. ${ }^{96}$ These results suggested that it may be difficult to increase the bioavailability of iron in beans that are rich in phytic acid and polyphenols. ${ }^{96}$ For achieving efficacious iron biofortification of beans, efforts must firstly move in the direction of selecting breeds for high iron and low phytate and polyphenol concentrations; then, of understanding the nutritional potential by evaluating the effects of cooking on iron concentration and the bioavailability of iron within the overall food/meal prepared from the grain. ${ }^{96,97}$

\section{Local production of micronutrient rich foods through home gardens, livestock, and small fish}

Dietary diversification or modification strategies employing agricultural interventions mostly aim to improve vitamin A status by introducing cultivation of $\beta$-carotene crops, including biofortified crops, and promoting consumption of vitamin A-rich foods. A systematic review by Masset and coworkers ${ }^{98}$ showed some evidence of an impact on vitamin A intake, but no evidence of an impact on iron intake. According to
Gibson and Anderson, ${ }^{90}$ strategies employing agricultural interventions, animal husbandry, or aquaculture have the potential to increase intakes of total or absorbable zinc. A systematic review ${ }^{12}$ showed that most agricultural studies, including home gardens, with or without animal production strategies were associated with increased dietary diversity, increased consumption of $\beta$-carotene rich vegetables and fruit, increased intake of other vegetables and fruit, increased intake of legumes, and improved complementary foods. Projects emphasizing production of $\beta$-carotene rich vegetables and fruit consistently reported higher intake of these vegetables and fruit, resulting in higher intakes of vitamin A. In some cases, the promotion of traditional leafy vegetables is included in these strategies. ${ }^{99}$ A review by Uusiku showed that indigenous green leafy vegetables have the potential to contribute toward micronutrient intake, ${ }^{100}$ but evidence on efficacy is lacking.

Integration of small-animal husbandry (such as fish, poultry, small livestock, and milking cows or goats) may increase dietary variety and availability of foods rich in preformed retinol. In Asia, for example, Helen Keller International has successfully implemented homestead food production programs with the goals of improving consumption of fruits and vegetables and animal-source foods through increased production, nutrition-related education, and increased income. ${ }^{101}$ Some small fish species in developing countries are rich sources of vitamin A, iron, and zinc, and are more affordable and accessible than the larger fish. These locally available small fish have potential as a cost-effective food-based strategy to enhance micronutrient intake; however, only a few studies are available, and more research is needed. ${ }^{102}$

Agricultural interventions can complement supplementation and fortification programs. In contrast to supplements and fortified foods, agricultural interventions deliver macroand micronutrients, fiber, and phytochemicals, all acting in synergy on health. Additional non-nutritional benefits include empowerment of women in the community, training, and income generation through production for sale in markets. ${ }^{103}$ Home gardening does not only have the potential to reduce the risk of vitamin A deficiency, ${ }^{89}$ but can help overall to reinforce household food and nutrition security and wellbeing. ${ }^{104}$ Successful introduction of these interventions requires demand creation and behavior change through promotion and education of household members. Consequently, the importance is clear of integrating well-designed behavior-change communications and careful consideration of active participation of women. ${ }^{39,40,99}$ Also, there is an urgent call for collaboration between the nutrition/health and agricultural sectors. 
Nutrition-sensitive agricultural interventions, when community-based, culturally acceptable, and economically feasible, have the potential to be the most sustainable long-term intervention of all for preventing multiple micronutrient deficiencies within an entire household and across generations. Although a few studies showed a positive impact of agricultural interventions on micronutrient intake and/or status, ${ }^{39,40,99}$ the body of information on the efficacy of these interventions to improve micronutrient status and health outcomes in at-risk populations is limited. More rigorous and better designed studies, and agreed standards and guidelines for evaluating these interventions, are needed to clarify the role of agricultural strategies in health and nutrition outcomes. ${ }^{12,98}$ Measuring nutritional outcomes (impact) of a food-based approach such as agricultural interventions is challenging because the entire diet cannot be controlled, and increased intake of one food item may result in a decreased intake of another food item, highlighting the importance of using appropriate indicators and the right study design. ${ }^{102}$

\section{Conclusion}

Micronutrient deficiencies can undoubtedly have profound influences on the health of at-risk populations. Poor households are the most vulnerable to micronutrient malnutrition, and more permanent solutions are still required. For example, anemia remains a public health problem of huge magnitude, yet little progress in controlling it has been achieved in the developing world.

Many scientific gaps still exist (lack of conclusive evidence about the effects of micronutrient supplementation or fortification on health outcomes, morbidity, and mortality; their potential adverse effects; and their optimal amount/ form/composition, frequency of use, and way of delivery) that hinder the development of robust public health guidance, owing to the paucity of well-designed studies/programs mainly from community-based settings; uncertainties originating from insufficient information on the biological mechanisms behind relationships between micronutrients and outcomes; dearth of attention to the bioavailability of the micronutrient (eg, iron in fortification and biofortification programs); and inconsistency of results (eg, lack of clarity about the effect of iron supplementation on pregnancy outcomes or growth in pediatric populations). Therefore, there is an urgent need to undertake further adequately powered long-term trials to fill the gaps.

Supplementation and fortification have a robust impact on the symptoms of micronutrient malnutrition. However, these strategies do not address the causes of the micronutrient malnutrition; ie, monotonous diets and low micronutrient bioavailability. A more comprehensive approach is needed to ultimately increase the availability of, access to, and consumption of adequate amounts of a variety of micronutrient-rich foods. To improve nutrition and health in the long-term, dietary strategies must necessarily integrate community-based, nutrition-sensitive agricultural interventions with nutrition education and female empowerment, returns on investments, marketing activities, and/or basic primary health care. It is critical to promote behaviors that support adequate intake, ensure availability of supply, and help to empower communities to be more self-reliant. ${ }^{89,105,106}$ Current evidence shows strategies promoting local production of food focus mostly on the improvement of vitamin A status. Biofortification may complement the existing micronutrient interventions by targeting rural areas where the access to commercially fortified food is limited, and the coverage of the public health system is low. However, to date the effects of most biofortified crops on functional indicators of micronutrient status must be still fully established.

To be successful, fortification and supplementation programs must have high-level government involvement. Fortification programs, for example, require political support, adequate marketing, and long-term commercial commitment. Government monitoring of fortification standards and enforcement of fortification regulations are critical, but often neglected. ${ }^{67}$ Governments should put into effect and correct laws and national monitoring standards; check that they are followed by both the public and the private sector; and guarantee access to and correct use of the product by the population - the vulnerable groups in particular. ${ }^{66}$

Evidence collected in the current paper confirms that in developing countries, different strategies target different populations; a combination of complementary strategies is needed. Program evaluation should consider both positive and negative effects, and include regular monitoring to detect both low and excessive intake of micronutrients.

\section{Disclosure}

The authors report no conflicts of interest in this work.

\section{References}

1. Nordin SM, Boyle M, Kemmer TM; Academy of Nutrition and Dietetics. Position of the academy of nutrition and dietetics: nutrition security in developing nations: sustainable food, water, and health. J Acad Nutr Diet. 2013;113(4):581-595.

2. Darnton-Hill I, Webb P, Harvey PW, et al. Micronutrient deficiencies and gender: social and economic costs. Am J Clin Nutr. 2005;81(5): $1198 \mathrm{~S}-1205 \mathrm{~S}$. 
3. Black RE, Allen LH, Bhutta ZA, et al; Maternal and Child Undernutrition Study Group. Maternal and child undernutrition: global and regional exposures and health consequences. Lancet. 2008;371(9608): 243-260.

4. Berti C, Biesalski HK, Gärtner R, et al. Micronutrients in pregnancy: current knowledge and unresolved questions. Clin Nutr. 2011;30(6): 689-701.

5. Shetty P. Addressing micronutrient malnutrition to achieve nutrition security. In: Thompson B, Amoroso L, editors. Combating Micronutrient Deficiencies: Food-Based Approaches. Rome, Italy: CAB International and FAO; 2011:28-40.

6. Burchi F, Fanzo J, Frison E. The role of food and nutrition system approaches in tackling hidden hunger. Int J Environ Res Public Health. 2011;8(2):358-373.

7. Gibson RS, Bailey KB, Gibbs M, Ferguson EL. A review of phytate, iron, zinc, and calcium concentrations in plant-based complementary foods used in low-income countries and implications for bioavailability. Food Nutr Bull. 2010;31(Suppl 2):S134-S146.

8. Bhutta ZA, Salam RA, Das JK. Meeting the challenges of micronutrient malnutrition in the developing world. Br Med Bull. 2013;106:7-17.

9. Stoltzfus RJ, Mullany L, Black RE. Iron deficiency anemia. In: Ezzati M, Lopez AD, Rodgers A, Murray CLJ, editors. Comparative Quantification of Health Risks: Global and Regional Burden of Disease Attributable to Selected Major Risk Factors. Geneva: World Health Organization; 2004:163-209.

10. Liberati A, Altman DG, Tetzlaff J, et al. The PRISMA statement for reporting systematic reviews and meta-analyses of studies that evaluate health care interventions: explanation and elaboration. Ann Intern Med. 2009;151(4):W65-W94

11. Gibson RS. Strategies for preventing multi-micronutrient deficiencies: a review of experiences with food-based approaches in developing countries. In: Thompson B, Amoroso L, editors. Combating Micronutrient Deficiencies: Food-Based Approaches. Rome, Italy: CAB International and FAO; 2011:7-27.

12. Girard AW, Self JL, McAuliffe C, Olude O. The effects of household food production strategies on the health and nutrition outcomes of women and young children: a systematic review. Paediatr Perinat Epidemiol. 2012;26(Suppl 1):205-222.

13. Imdad A, Bhutta ZA. Routine iron/folate supplementation during pregnancy: effect on maternal anemia and birth outcomes. Paediatr Perinat Epidemiol. 2012;26 Suppl 1:168-177.

14. Peña-Rosas JP, De-Regil LM, Dowswell T, Viteri FE. Daily oral iron supplementation during pregnancy. Cochrane Database Syst Rev. 2012;12:CD004736.

15. Pasricha S-R, Hayes E, Kalumba K, Biggs B-A. Effect of daily iron supplementation on health in children aged 4-23 months: a systematic review and meta-analysis of randomised controlled trials. Lancet Glob Health; 2013;1(2):e77-e86.

16. Sachdev H, Gera T, Nestel P. Effect of iron supplementation on mental and motor development in children: systematic review of randomised controlled trials. Public Health Nutr. 2005;8(2):117-132.

17. Sachdev H, Gera T, Nestel P. Effect of iron supplementation on physical growth in children: systematic review of randomised controlled trials Public Health Nutr. 2006;9(7):904-920.

18. Gera T, Sachdev HP, Nestel P, Sachdev SS. Effect of iron supplementation on haemoglobin response in children: systematic review of randomised controlled trials. J Pediatr Gastroenterol Nutr. 2007;44(4):468-486.

19. Vucic V, Berti C, Vollhardt C, et al. Effect of iron intervention on growth during gestation, infancy, childhood, and adolescence: a systematic review with meta-analysis. Nutr Rev. 2013;71(6):386-401.

20. Assunção MC, Santos IS. [Effect of food fortification with iron on childhood anemia: a review study]. Cad Saude Publica. 2007;23(2):269-281. Portuguese.

21. Assunção MC, Santos IS, Barros AJ, Gigante DP, Victora CG. Flour fortification with iron has no impact on anemia in urban Brazilian children. Public Health Nutr. 2012;15(10):1796-1801.
22. Dutra-de-Oliveira JE, Marchini JS, Lamounier J, Almeida CA. IronFortified Drinking Water Studies for the Prevention of Children's Anemia in Developing Countries. Anemia. 2011;2011:815194.

23. Miglioranza LH, Breganó JW, Dichi I, Matsuo T, Dichi JB, Barbosa DS. Effectiveness of fortification of corn flour-derived products with hydrogen-reduced elemental iron on iron-deficiency anemia in children and adolescents in southern Brazil. Public Health Nutr. 2009;12(2): 244-248.

24. Das JK, Salam RA, Kumar R, Bhutta ZA. Micronutrient fortification of food and its impact on woman and child health: a systematic review. Syst Rev. 2013;2:67.

25. Gera T, Sachdev HS, Boy E. Effect of iron-fortified foods on hematologic and biological outcomes: systematic review of randomized controlled trials. Am J Clin Nutr. 2012;96(2):309-324.

26. Fekete K, Berti C, Trovato M, et al. Effect of folate intake on health outcomes in pregnancy: a systematic review and meta-analysis on birth weight, placental weight and length of gestation. Nutr J. 2012;11:75.

27. Luabeya KK, Mpontshane N, Mackay M, et al. Zinc or multiple micronutrient supplementation to reduce diarrhea and respiratory disease in South African children: a randomized controlled trial. PLoS One. 2007;2(6):e541.

28. Walker CL, Black RE. Zinc for the treatment of diarrhoea: effect on diarrhoea morbidity, mortality and incidence of future episodes. Int $J$ Epidemiol. 2010;39 Suppl 1:i63-i69.

29. Chaffee BW, King JC. Effect of zinc supplementation on pregnancy and infant outcomes: a systematic review. Paediatr Perinat Epidemiol. 2012;26 Suppl 1:118-137.

30. Aggarwal R, Sentz J, Miller MA. Role of zinc administration in prevention of childhood diarrhea and respiratory illnesses: a metaanalysis. Pediatrics. 2007;119(6):1120-1130.

31. Roth DE, Richard SA, Black RE. Zinc supplementation for the prevention of acute lower respiratory infection in children in developing countries: meta-analysis and meta-regression of randomized trials. Int J Epidemiol. 2010;39(3):795-808.

32. Soofi S, Cousens S, Iqbal SP, et al. Effect of provision of daily zinc and iron with several micronutrients on growth and morbidity among young children in Pakistan: a cluster-randomised trial. Lancet. 2013;382(9886):29-40.

33. Rosado JL, Hambidge KM, Miller LV, et al. The quantity of zinc absorbed from wheat in adult women is enhanced by biofortification. J Nutr. 2009;139(10):1920-1925.

34. Mayo-Wilson E, Imdad A, Herzer K, Yakoob MY, Bhutta ZA. Vitamin A supplements for preventing mortality, illness, and blindness in children aged under 5: systematic review and meta-analysis. BMJ. 2011;343:d5094.

35. Haider BA, Bhutta ZA. Neonatal vitamin A supplementation for the prevention of mortality and morbidity in term neonates in developing countries. Cochrane Database Syst Rev. 2011;(10):CD006980.

36. Thapa S, Choe MK, Retherford RD. Effects of vitamin A supplementation on child mortality: evidence from Nepal's 2001 Demographic and Health Survey. Trop Med Int Health. 2005;10(8):782-789.

37. Semba RD, de Pee S, Sun K, Bloem MW, Raju VK. The role of expanded coverage of the national vitamin A program in preventing morbidity and mortality among preschool children in India. J Nutr. 2010;140(1):208S-212S.

38. Grover DS, Pee Sd, Sun K, Raju VK, Bloem MW, Semba RD. Vitamin A supplementation in Cambodia: program coverage and association with greater maternal formal education. Asia Pac J Clin Nutr. 2008;17(3):446-450.

39. Hotz C, Loechl C, Lubowa A, et al. Introduction of $\beta$-carotene-rich orange sweet potato in rural Uganda resulted in increased vitamin A intakes among children and women and improved vitamin A status among children. J Nutr. 2012;142(10):1871-1880.

40. Hotz C, Loechl C, de Brauw A, et al. A large-scale intervention to introduce orange sweet potato in rural Mozambique increases vitamin A intakes among children and women. Br J Nutr. 2012;108(1): $163-176$. 
41. Bhutta ZA, Imdad A, Ramakrishnan U, Martorell R. Is it time to replace iron folate supplements in pregnancy with multiple micronutrients? Paediatr Perinat Epidemiol. 2012;26 Suppl 1:27-35.

42. Fall CH, Fisher DJ, Osmond C, Margetts BM; Maternal Micronutrient Supplementation Study Group. Multiple micronutrient supplementation during pregnancy in low-income countries: a meta-analysis of effects on birth size and length of gestation. Food Nutr Bull. 2009; 30(Suppl 4):S533-S546.

43. Ronsmans C, Fisher DJ, Osmond C, Margetts BM, Fall CH; Maternal Micronutrient Supplementation Study Group. Multiple micronutrient supplementation during pregnancy in low-income countries: a metaanalysis of effects on stillbirths and on early and late neonatal mortality. Food Nutr Bull. 2009;30(Suppl 4):S547-S555.

44. Eichler K, Wieser S, Rüthemann I, Brügger U. Effects of micronutrient fortified milk and cereal food for infants and children: a systematic review. BMC Public Health. 2012;12:506.

45. De-Regil LM, Suchdev PS, Vist GE, Walleser S, Peña-Rosas JP. Home fortification of foods with multiple micronutrient powders for health and nutrition in children under two years of age. Cochrane Database Syst Rev. 2011;(9):CD008959.

46. Best C, Neufingerl N, Del Rosso JM, Transler C, van den Briel T, Osendarp S. Can multi-micronutrient food fortification improve the micronutrient status, growth, health, and cognition of schoolchildren? A systematic review. Nutr Rev. 2011;69(4):186-204.

47. Salam RA, MacPhail C, Das JK, Bhutta ZA. Effectiveness of Micronutrient Powders (MNP) in women and children. BMC Public Health. 2013;13 Suppl 3:S22.

48. Suchdev PS, De-Regil LM, Walleser S, Vist GE, Peña-Rosas JP. Multiple micronutrient powders for home (point of use) fortification of foods in pregnant women: a systematic review. Geneva, World Health Organization: WHO e-Library of Evidence for Nutrition Actions; 2011.

49. Radhika MS, Nair KM, Kumar RH, et al. Micronized ferric pyrophosphate supplied through extruded rice kernels improves body iron stores in children: a double-blind, randomized, placebo-controlled midday meal feeding trial in Indian schoolchildren. Am J Clin Nutr. 2011;94(5):1202-1210.

50. Makola D, Ash DM, Tatala SR, Latham MC, Ndossi G, Mehansho H. A micronutrient-fortified beverage prevents iron deficiency, reduces anemia and improves the hemoglobin concentration of pregnant Tanzanian women. J Nutr. 2003;133(5):1339-1346.

51. Cetin I, Berti C, Calabrese S. Role of micronutrients in the periconceptional period. Hum Reprod Update. 2010;16(1):80-95.

52. Czeizel AE. Periconceptional folic acid-containing multivitamin supplementation for the prevention of neural tube defects and cardiovascular malformations. Ann Nutr Metab. 2011;59(1):38-40.

53. Allen LH, Peerson JM; and the Maternal Micronutrient Supplementation Study Group (MMSSG). Impact of multiple micronutrient versus ironfolic acid supplements on maternal anemia and micronutrient status in pregnancy. Food Nutr Bull. 2009;30(Suppl 4):S527-S532.

54. WHO. Guideline: Vitamin A Supplementation in Pregnant Women. Geneva: World Health Organization, 2011a.

55. WHO. Guideline: Vitamin A Supplementation in Postpartum Women. World Health Organization, $2011 \mathrm{~b}$.

56. Pasricha SR, Drakesmith H, Black J, Hipgrave D, Biggs BA. Control of iron deficiency anemia in low- and middle-income countries. Blood. 2013;121(14):2607-2617.

57. Okebe JU, Yahav D, Shbita R, Paul M. Oral iron supplements for children in malaria-endemic areas. Cochrane Database Syst Rev. 2011;(10):CD006589.

58. Lowe NM, Dykes FC, Skinner AL, et al. EURRECA-Estimating zinc requirements for deriving dietary reference values. Crit Rev Food Sci Nutr. 2013;53(10):1110-1123.

59. Imdad A, Herzer K, Mayo-Wilson E, Yakoob MY, Bhutta ZA. Vitamin A supplementation for preventing morbidity and mortality in children from 6 months to 5 years of age. Cochrane Database Syst Rev. 2010;(12):CD008524.
60. Ahmed T, Mahfuz M, Ireen S, et al. Nutrition of children and women in Bangladesh: trends and directions for the future. J Health Popul Nutr. 2012;30(1):1-11.

61. Chen H, Zhuo Q, Yuan W, Wang J, Wu T. Vitamin A for preventing acute lower respiratory tract infections in children up to seven years of age. Cochrane Database Syst Rev. 2008;(1):CD006090.

62. Latham M. The great vitamin A fiasco. World Nutr. 2010;1(1):12-45.

63. Kapil U, Sachdev HP. Massive dose vitamin A programme in India - need for a targeted approach. Indian J Med Res. 2013;138(3):411-417.

64. Chow J, Darley S, Laxminarayan R. Cost-effectiveness of disease interventions in India. Washington, DC: Resources for the future, 2007.

65. Harrison GG. Public Health interventions to combat micronutrient deficiencies. Public Health Reviews. 2010;32(1):256-266.

66. Victora CG, Barros FC, Assunção MC, Restrepo-Méndez MC, Matijasevich A, Martorell R. Scaling up maternal nutrition programs to improve birth outcomes: a review of implementation issues. Food Nutr Bull. 2012;33(Suppl 2):S6-S26.

67. Fiedler JL, Sanghvi TG, Saunders MK. A review of the micronutrient intervention cost literature: program design and policy lessons. Int $J$ Health Plann Manage. 2008;23(4):373-397.

68. UNICEF. Tracking progress on child maternal nutrition: a survival and development priority. UNICEF, 2009.

69. Aguayo VM, Baker SK, Crespin X, Hamani H, MamadoulTaïbou A. Maintaining high vitamin A supplementation coverage in children: lessons from Niger. Food Nutr Bull. 2005;26(1):26-31.

70. Stoltzfus RJ. Iron interventions for women and children in low-income countries. J Nutr. 2011;141(4):756S-762S.

71. Sanghvi TG, Harvey PW, Wainwright E. Maternal iron-folic acid supplementation programs: evidence of impact and implementation. Food Nutr Bull. 2010;31(Suppl 2):S100-S107.

72. Dary O, Mora JO; International Vitamin A Consultative Group. Food fortification to reduce vitamin A deficiency: International Vitamin A Consultative Group recommendations. J Nutr. 2002;132(Suppl 9): 2927S-2933S.

73. Self JL, Serdula M, Dowswell T, De-Regil LM. Fortification of condiments and seasonings with iron for preventing anemia and improving health. Cochrane Database Syst Rev. 2012;2:CD009604.

74. Van Thuy P, Berger J, Nakanishi Y, Khan NC, Lynch S, Dixon P. The use of NaFeEDTA-fortified fish sauce is an effective tool for controlling iron deficiency in women of childbearing age in rural Vietnam. $J$ Nutr. 2005;135(11):2596-2601

75. Van Thuy P, Berger J, Davidsson L, et al. Regular consumption of NaFeEDTA-fortified fish sauce improves iron status and reduces the prevalence of anemia in anemic Vietnamese women. Am J Clin Nutr. 2003;78(2):284-290.

76. Fiedler JL, Afidra R. Vitamin A fortification in Uganda: comparing the feasibility, coverage, costs, and cost-effectiveness of fortifying vegetable oil and sugar. Food Nutr Bull. 2010;31(2):193-205.

77. Andersson M, Karumbunathan V, Zimmermann MB. Global iodine status in 2011 and trends over the past decade. J Nutr. 2012;142(4):744-750.

78. Allen L, de Benoist B, Dary O, Hurrell R, editors. Guidelines on food fortification with micronutrients. World Health Organization/Food and Agricultural Organization of the United Nations (WHO/FAO): Geneva, Switzerland; 2006.

79. Chavasit V. Keys to sustainable food fortification programs in developing countries. Compr Rev Food Sci Food Safety. 2008;7(4):382-385.

80. Hurrell R, Ranum P, de Pee S, et al. Revised recommendations for iron fortification of wheat flour and an evaluation of the expected impact of current.

81. Nestel P, Briend A, de Benoist B, et al. Complementary food supplements to achieve micronutrient adequacy for infants and young children. J Pediatr Gastroenterol Nutr. 2003;36(3):316-328.

82. Smuts CM, Lombard CJ, Benadé AJ, et al; International Research on Infant Supplementation (IRIS) Study Group. Efficacy of a foodlet-based multiple micronutrient supplement for preventing growth faltering, anemia, and micronutrient deficiency of infants: the four country IRIS trial pooled data analysis. $J$ Nutr. 2005;135(3):631S-638S. 
83. Young SL, Blanco I, Hernandez-Cordero S, Pelto GH, Neufeld LM. Organoleptic properties, ease of use, and perceived health effects are determinants of acceptability of micronutrient supplements among poor Mexican women. J Nutr. 2010;140(3):605-611.

84. Chaparro CM, Dewey KG. Use of lipid-based nutrient supplements (LNS) to improve the nutrient adequacy of general food distribution rations for vulnerable sub-groups in emergency settings. Matern Child Nutr. 2010;6 Suppl 1:1-69.

85. Hirve S, Martini E, Juvekar SK, et al. Delivering Sprinkles Plus through the Integrated Child Development Services (ICDS) to reduce anemia in pre-school children in India. Indian J Pediatr. 2013;80(12): 990-995.

86. Zlotkin SH, Schauer C, Christofides A, Sharieff W, Tondeur MC, Hyder SM. Micronutrient sprinkles to control childhood anemia. PLoS Med. 2005;2(1):e1.

87. Suchdev PS, Shah A, Jefferds ME, et al. Sustainability of market-based community distribution of Sprinkles in western Kenya. Matern Child Nutr. 2013;9 Suppl 1:78-88.

88. Bhutta ZA, Ahmed T, Black RE, et al; Maternal and Child Undernutrition Study Group. What works? Interventions for maternal and child undernutrition and survival. Lancet. 2008;371(9610):417-440.

89. Faber M, van Jaarsveld PJ. The production of provitamin A-rich vegetables in home-gardens as a means of addressing vitamin A deficiency in rural African communities. J Sci Food Agric. 2007;87(3): 366-377.

90. Gibson RS, Anderson VP. A review of interventions based on dietary diversification or modification strategies with the potential to enhance intakes of total and absorbable zinc. Food Nutr Bull. 2009; 30(Suppl 1):S108-S143.

91. Nestel P, Bouis HE, Meenakshi JV, Pfeiffer W. Biofortification of staple food crops. J Nutr. 2006;136(4):1064-1067.

92. Bouis HE, Hotz C, McClafferty B, Meenakshi JV, Pfeiffer WH. Biofortification: a new tool to reduce micronutrient malnutrition. Food Nutr Bull. 2011;32(Suppl 1):S31-S40.

93. Hotz C, McClafferty B. From harvest to health: challenges for developing biofortified staple foods and determining their impact on micronutrient status. Food Nutr Bull. 2007;28(Suppl 2):S271-S279.

94. Bouis HE, Welch RM. Biofortification - A sustainable agricultural strategy for reducing micronutrient malnutrition in the global South. Crop Sci. 2010;50(Suppl 1):S-20-S-32.

95. Blair MW. Mineral biofortification strategies for food staples: the example of common bean. J Agric Food Chem. 2013;61(35):8287-8294.
96. Petry N, Egli I, Gahutu JB, Tugirimana PL, Boy E, Hurrell R. Stable iron isotope studies in Rwandese women indicate that the common bean has limited potential as a vehicle for iron biofortification. $J$ Nutr. 2012;142(3):492-497.

97. Nutti M, Watanabe E, de Carvalho JLV, et al. Strategies for biofortification in Brazil. In: Serageldin I, Massod E, El-Faham M, El-Wakil M, editors. From Promises to Practice: Applications of Science and Technology in Food, Healthcare, Energy and Environment. ALICE 2010:177-193. http://www.alice.cnptia.embrapa.br/bitstream/ doc/865202/1/2010002.pdf. Accessed May 13, 2014.

98. Masset E, Haddad L, Cornelius A, Isaza-Castro J. A systematic review of agricultural interventions that aim to improve nutritional status of children. London: EPPI-Centre, Social Science Research Unit, Institute of Education, University of London, 2011

99. Faber M, Laurie S. A home gardening approach developed in South Africa to address vitamin A deficiency. In: Thompson B, Amoroso L, editors. Combating Micronutrient Deficiencies: Food-Based Approaches. Rome, Italy: CAB International and FAO; 2011:163-182.

100. Uusiku NP, Oelofse A, Duodu KG, Bester MJ, Faber M. Nutritional value of leafy vegetables of sub-Saharan Africa and their potential contribution to human health: a review. J Food Comp Anal. 2010;23(6): 499-509.

101. Olney DK, Talukder A, Iannotti LL, Ruel MT, Quinn V. Assessing impact and impact pathways of a homestead food production program on household and child nutrition in Cambodia. Food Nutr Bull. 2009;30(4):355-369.

102. Kawarazuka N, Béné C. The potential role of small fish species in improving micronutrient deficiencies in developing countries: building evidence. Public Health Nutr. 2011;14(11):1927-1938.

103. Thomson B, Amoroso L. Introduction. In: Thompson B, Amoroso L, editors. Combating Micronutrient Deficiencies: Food-Based Approaches. Rome, Italy: CAB International and FAO; 2011:1-6.

104. Galhena DH, Freed R, Maredia KM. Home gardens: a promising approach to enhance household food security and wellbeing. Agric Food Security. 2013;2:8.

105. Bhutta ZA, Darmstadt GL, Hasan BS, Haws RA. Community-based interventions for improving perinatal and neonatal health outcomes in developing countries: a review of the evidence. Pediatrics. 2005;115(Suppl 2):519-617.

106. Dewey KG, Adu-Afarwuah S. Systematic review of the efficacy and effectiveness of complementary feeding interventions in developing countries. Matern Child Nutr. 2008;4 Suppl 1:24-85.
Nutrition and Dietary Supplements

\section{Publish your work in this journal}

Nutrition and Dietary Supplements is an international, peer-reviewed, open access journal focusing on research into nutritional requirements in health and disease, impact on metabolism and the identification and optimal use of dietary strategies and supplements necessary for normal growth and development. The journal welcomes papers covering

\section{Dovepress}

original research, basic science, clinical \& epidemiological studies, reviews and evaluations, guidelines, expert opinion and commentary, case reports and extended reports. The manuscript management system is completely online and includes a very quick and fair peer-review system, which is all easy to use. 